Z. Mohtasham Amiri ${ }^{{ }^{* 1}}$, M.A. Joafshani $^{2}$, T. Bashari Sheikhani $^{3}$, M. Kiaei ${ }^{3}$

1. Full Professor, Preventive and Social Medicine Department Guilan University of Medical Sciences, Rasht, Iran

2 Assistant Professor,

Preventive and Social Medicine Department, Guilan University of Medical Sciences, Rasht, Iran

3. General Physician, Guilan University of Medical Sciences, Rasht, Iran

*Corresponding Author: Full Professor in Preventive and Social Medicine, Medical Faculty, Guilan University of Medical Sciences, Rasht, Iran

Clinical Research Development, Pour-Sina Hospital, Rasht, Iran

Tel: 013-33368773

E-mail: mohtashamaz@yahoo.com mohtasham@gums.ac.ir

\section{Impact of Birth Weight on Over Weight and Obesity in Preschool Children}

\author{
Received:29 March 2016; Accepted:31 Dec.2016
}

\section{Abstract}

Introduction: Childhood obesity is a serious public health problem and epidemiological studies are important to identify predictive factors. It is the aim of this study to analyze birth weight as a predict factor of obesity among preschool children.

Methods: 554 preschool children (4-6years-old) were selected by multistage random sampling from rural areas in Rasht. Data collected from health records of households of health systems and interview with parents. Weight and height of children was measured. We considered children with weight- for- height $>/=85$ th percentile to be overweight and weight- for- height $>/=95$ th percentile to be obese. Data Analysis was done with SPSS Software Ver. 16. descriptive statistics and X2 was used.

Results: Overall, 256 children(46.4\%) were boys, 37 (6.7\%) of children were overweight and 36 $(6.5 \%)$ of these were obese. At birth, $42(7.2 \%)$ of children were low birth weight and $28(5 \%)$ of them were high birth weight. There was a positive relation between birth weight and catch -up weigh in other periods of life but There were not any differences between overweigh and obesity rate with low birth weight, appropriate birth weight and high birth weight in children.

Conclusion: It seems that birth weight does not predict obesity in childhood and environmental factors have more power on obesity that must be noticed.

Keywords: Obesity, Overweight, Preschool Children, Birth Weight 



\section{بررسى تأثير وزن هنكَام تولد بر جاقى و افزايش وزن كودكان يبشدبستانى}

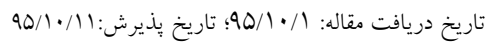

حكيله

مقدمه و هدف: جاقى كو دكان يكى مشكل بهداشت عمومى مىباشد كـه مطالعـات إيــميولوزيك بـراى شناسـيى عوامـل ييشبينى كننده آن بسيار مهم هستند.هدف از اين مطالعه بررسى تأثير وزن هنگام تولد بر روى جاقى كودكان بيشدبسـتانى

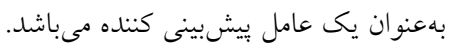

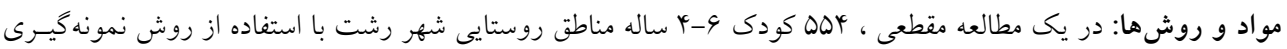
جندمرحلهاى تصادفى انتخاب شدند. دادههاى موردنياز از بدو تولد تاكنون از يروندههاى بهداشـتى و مصـاحبه بـا والــين

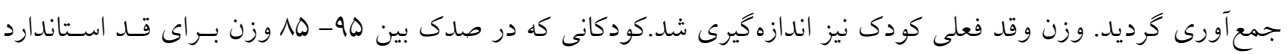

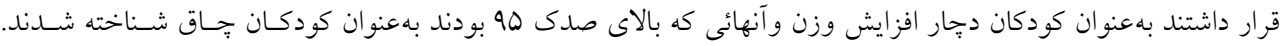

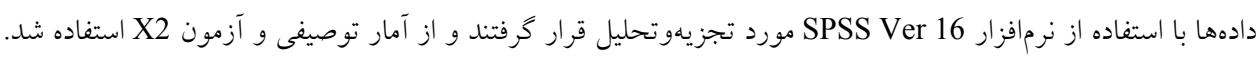

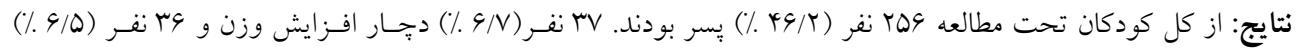

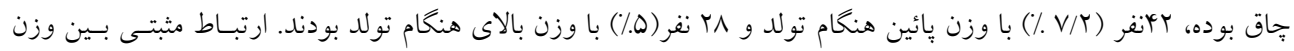

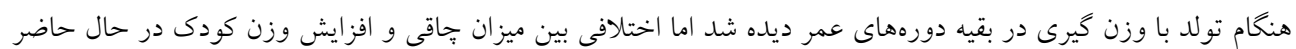
بر اساس وزن هنگام تولد بالا يا بائين ديده نشد.

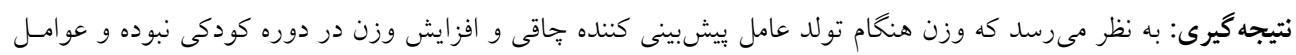
محيطى تأثير بيشترى دارند كه بايد مدنظر قرار كيرند. كلمات كليدى: جاقى، افزايش وزن، كودكان بيشدبستانى، وزن هنگحام تولد

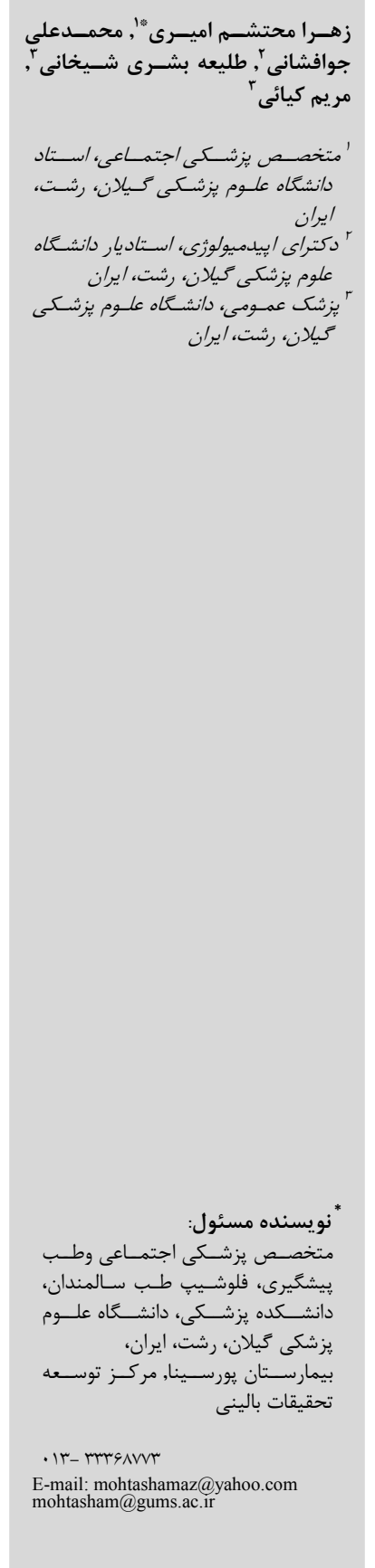


والدينشان اضـافهوزن ندارنسـ دجــار ايسن مشـكل مسىشـوند. طـى

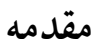
تحقيقاتى كه در سـال هـاى اخيـر انجـامشــه وضـعيت اقتصـادى-

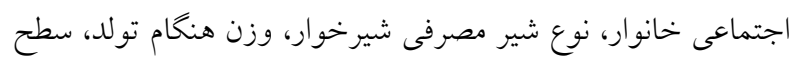

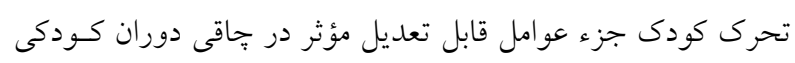

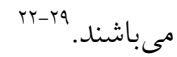
در اين ميان وزن هنخام تولد يكى از مسـائل بحـثتبرانخيـز در

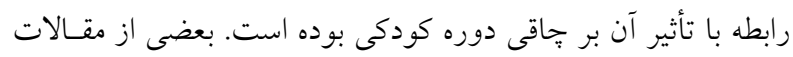

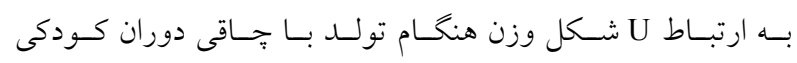

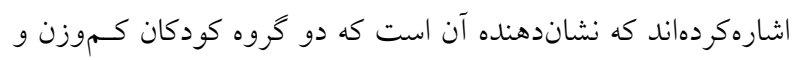

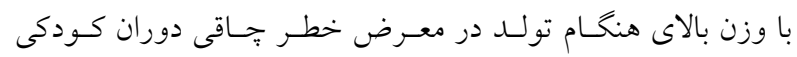
مى باشند و در بعضى ديخر آن را J شكل دانسته انـد كـه حساكى از

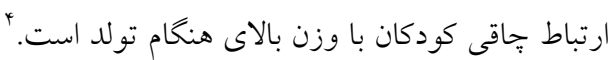

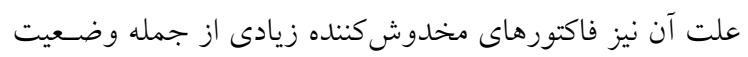

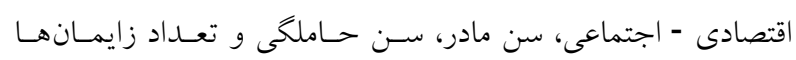

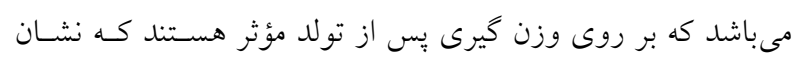

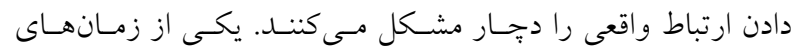

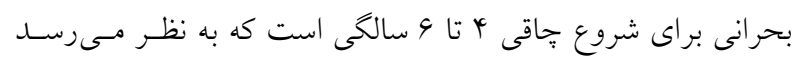

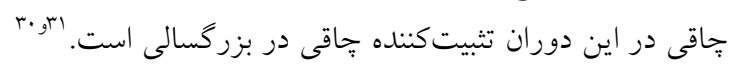

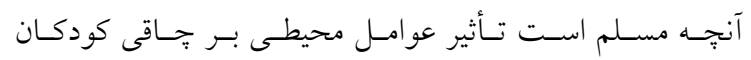
در جوامع مختلـف بـا وضسعيت اجتمـاعى و اقتصـادى متفـاوت و و

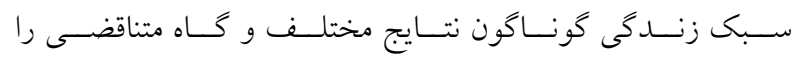
نشان مى دهد. بنابراين شناسـايى افـراد در معـرض خطـر و عوامـل قابل تعديل جهت توصيه هاى بعدى براى زندگى سـالمتـــ و تغييـر

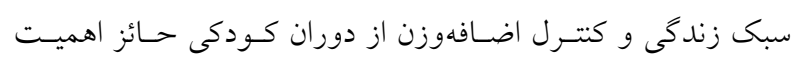

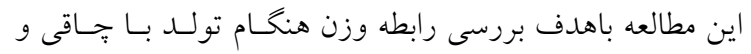

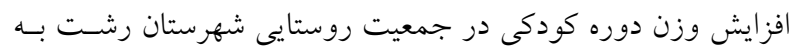
اجرا در آمده است.

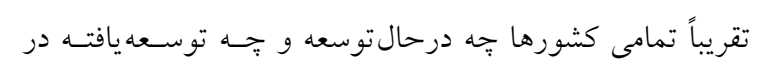

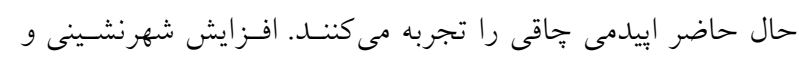

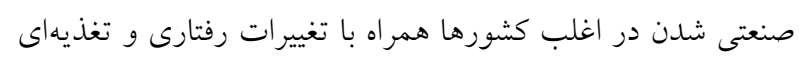

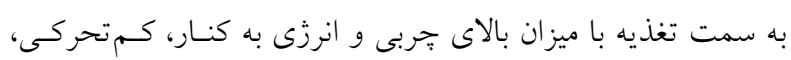

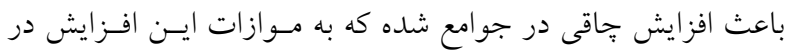
سى سال كذشته، افزايش بيمارىهاى قلبى و عروقى و ديابـت نـوع

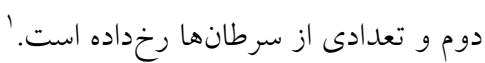

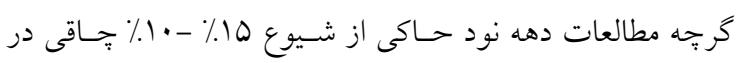

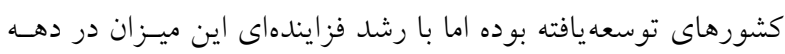

كذشته افزايشيافته و به بيش از دو برابر دهه قبل رسيده است.

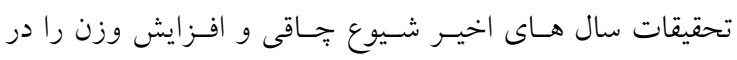

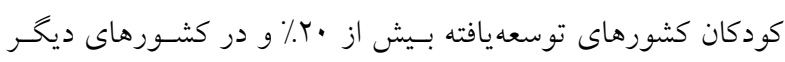
برحسب شر ايط مختلف اجتماعى و اقتصادى متفاوت ذكر كردهانــ اما در اين ميان كشورهاى حد مرزى توسعه به دليل تغييرات رفتارى

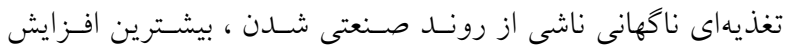
شيوع را داشتهاند.

عليرغم اينكه در مطالعات مختلف ديدهشـــه كـهـ جـاقى ســين

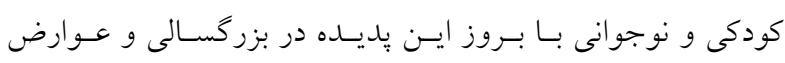

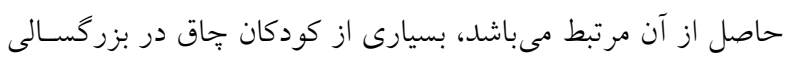

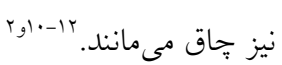
مطالعات انجامشده در ايران نيز حاكى از شيوع بـالاى جـاقى و

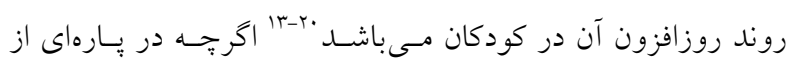

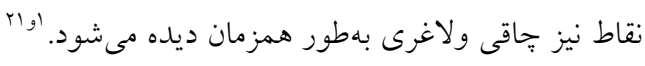

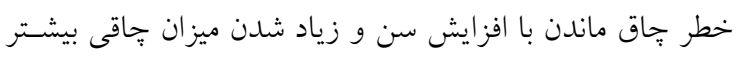

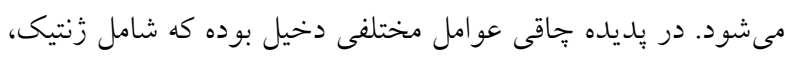

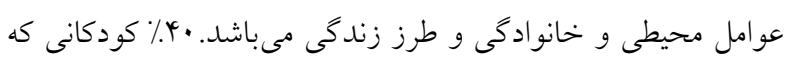

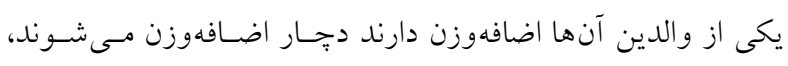

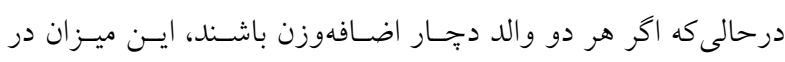

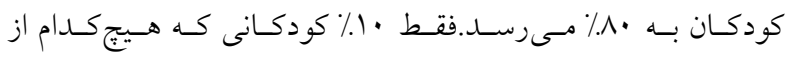




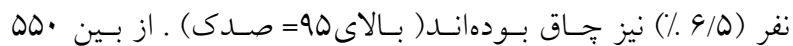

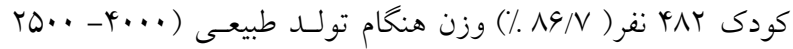

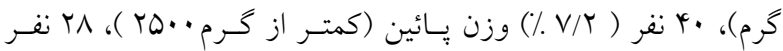

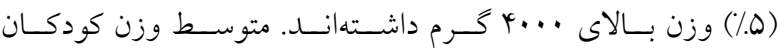

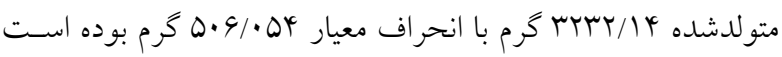

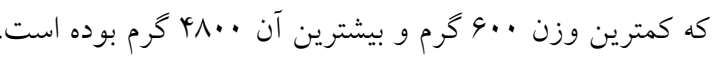

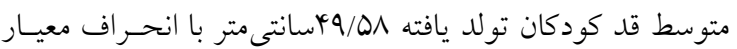

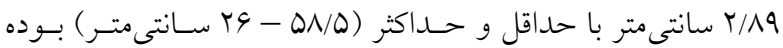
است. متوسط وزن كودكان در 9 ماهكى و يـكسـالكى بـهـ ترتيـب

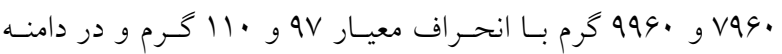

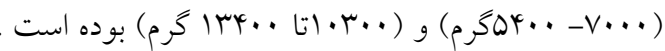

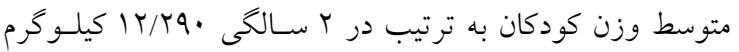
با انحراف معيار צץ/ ا كيلوگرم و دامنه (

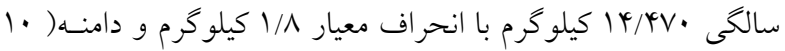

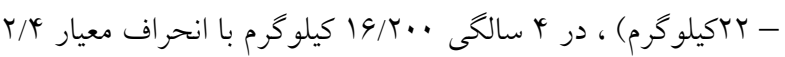

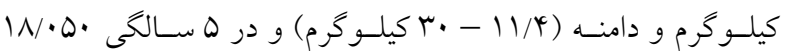

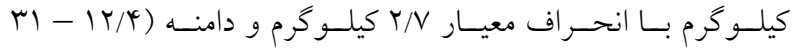
كيلو گرم) بوده است (جدول r ).

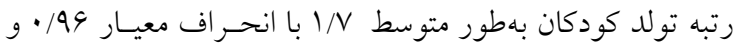

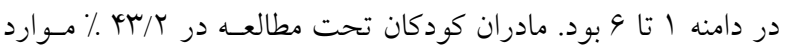

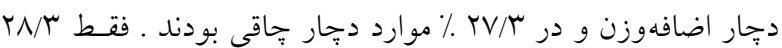

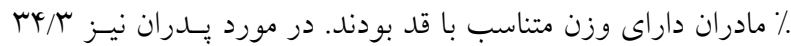
\% داراى افزايش وزن وه/9 \% دجار جاقى بودند(جدول ץ).

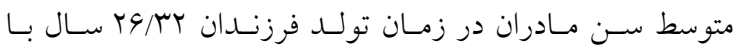
انحراف معيـار ه/9 سـال در دامنـه ( •ه - ه ال سـال) بـوده اسـت.

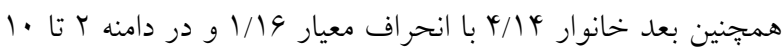

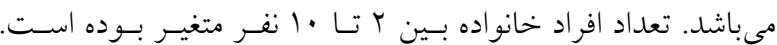
بلمور متوسط بيشتر خانوادهها با نفر بودهاند.

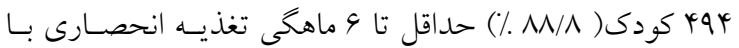

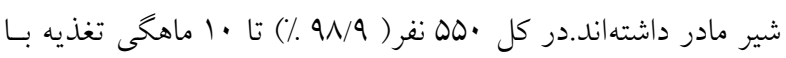
شير مادر را ادامه دادهاند.

\section{مواد و روشها}

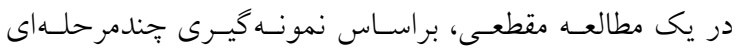
تصادفى از كل كودكان مناطق روستايى شهرستان رشـت بـر اسـاس يرونده خانوار در خانههاى بهداشت، تعداد وهاد كـودى و-4 سـاله

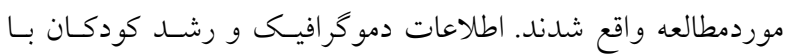
هماهنخى بهورزان و تيم تحقيق از يروندهها اسـتخراج شــده و وارد جك ليست مربوطه گرديد. همجنــين كودكـان و والـدين آنهـا نيـز

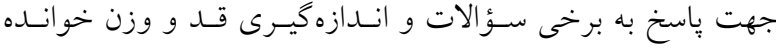

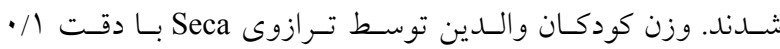
كيلوگرم و قد با دقت // • سانتىمتر توسط قد سنج اندازه وزيرى شد.

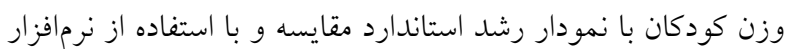
Epi info 2000 والدين نيز از شاخص توده بــدن (BMI )كـه در تقسـيمبنـدىهـاى اضافهوزن و جاقى بكار مى رود استفاده شد.براساس تعريـف جــاقى BMI صدى > ه ه در كودكـان و در بزركسـالان • • (obesity )

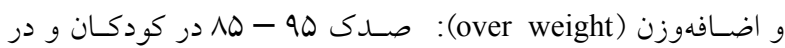

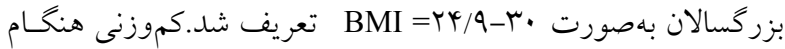

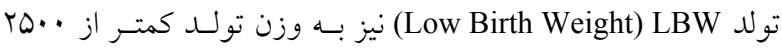
كرم و وزن بالاى هنگام تولد (Macrosomia ) به وزن هنخـام تولـد بالاى .... ب عرم اطلاق شد. يس از اتمام كار، دادهها وارد كامييوتر شده با استفاده از نرمافزار تجزيه وتحليل انجام شد. از آمار توصيفى و تحليلى SPSS ver. 16 همجِون T Test , X Square استفاده كرديد. از ميان

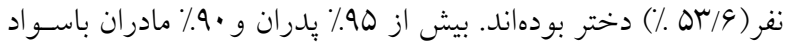
بودند و تنها 1/V ٪ مادران شاغل بودند(جدول ()).

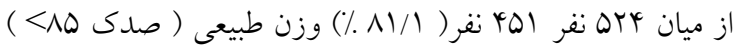

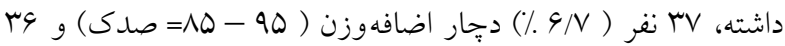




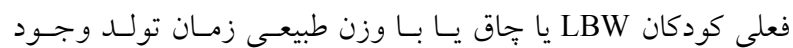

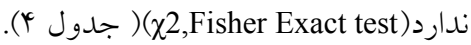

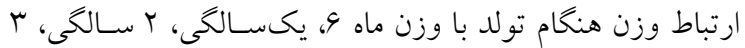

و ب و ه سالكى كاملاً معنادار بوده است.

$r=\cdot r \mu r$ r

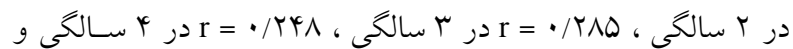

D

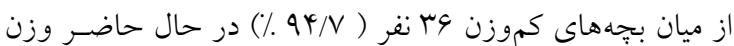

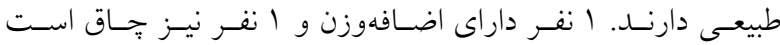

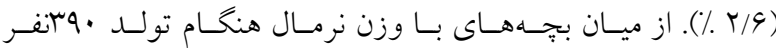

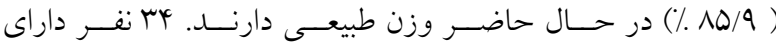

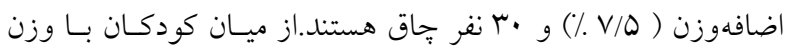

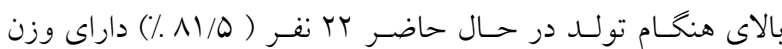

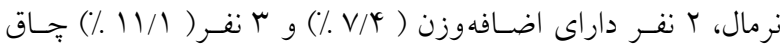
هستند. (جدول شـماره ؟).بنـابراين تفـاوت معنـادارى در وضـعيت

جدول ا: مشخصات دمو گرافيك كودكان تحت مطالعه

\begin{tabular}{|c|c|c|c|}
\hline درصد & تعداد & حالت ل & متغير \\
\hline$\Delta H / 9$ & rqA & دختر & 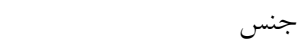 \\
\hline 49 & TOS & 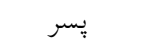 & \\
\hline $1 \cdot 19$ & $\Delta q$ & > o plo & تغذيه انحصارى با شير مادر \\
\hline$\Lambda / \wedge$ & rq4 & o 4 & \\
\hline$r / \Delta$ & 14 & بلى بلى & ارتباط فاميلى پدر و مادر \\
\hline $99 / 1$ & orA & 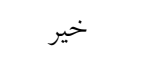 & \\
\hline$\Delta / r$ & rq & 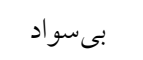 & سطح سواد يدر \\
\hline $1 \cdot / 1$ & 4. & ابتدايى & \\
\hline$V \backslash / \Lambda$ & $r 99$ & ر ماهنمايى & \\
\hline $11 / \mathrm{V}$ & 90 & دييلم & \\
\hline$\cdot / r$ & 1 & بالاى دييلم & \\
\hline V & rq & بي سواد & سطح سو اد مادر \\
\hline 11 & 91 & ابتدايى & \\
\hline $9 \pi / 1$ & rol & راهنمايى & \\
\hline $\mid \Lambda / r$ & $1 . r$ & ديبلم & \\
\hline$\cdot / r$ & 1 & بالاى ديبلم & \\
\hline $1 / \pi$ & V & بلى بلى & شاغل بودن مادر \\
\hline $9 \mathrm{~V} / \mathrm{\Lambda}$ & DFF & 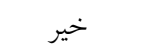 & \\
\hline
\end{tabular}

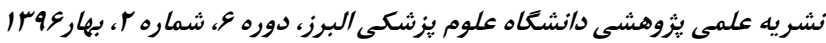


جدول r: ميانگين و انحراف معيار وزن و قد كودكان تحت مطالعه بر اساس سن

\begin{tabular}{|c|c|c|c|}
\hline حداقل - حداكثر & انحر اف معيار & ميانگين & 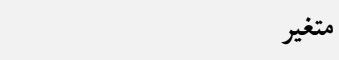 \\
\hline $4 \wedge \cdots-9 \cdots$ & $0.9 / .04$ & TYMT/YY & وزن كودى در بدو تولد(كرم) \\
\hline$V-\Delta / \varphi$ &.$/ 9 V$ & $V / 99$ & وزن كودكان در و ماهكى(Kg) \\
\hline $\mid r / 4-1 \cdot / r$ & $1 / 1$ & $9 / 99$ & وزن كودكان در ا سالكى(Kg) \\
\hline$I V-\Lambda / \Lambda$ & $1 / 49$ & $1 r / r 9$ & وزن كودكان در ץ سالخى(Kg) \\
\hline$r r-1$. & $1 / 1$ & $\mid \varphi / \varphi v$ & وزن كودكان در r سالخى(Kg) \\
\hline$r \cdot-11 / 4$ & $r / 4$ & $19 / r$ & وزن كودكان در † سالكى(Kg) \\
\hline$\mu|-| r / 4$ & $r / v$ & $1 N \cdot 0$ & وزن كودكان در ه سالكى(Kg) \\
\hline
\end{tabular}

جدول r: توزيع وضعيت فيزيكى بدنى والدين و كودكان تحت مطالعه

\begin{tabular}{|c|c|c|c|}
\hline$\Lambda 1 / 1$ & $Y Q 1$ & طبيعى & وضعيت بدنى كودكان در حال حاضر \\
\hline G/V & rv & 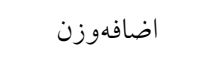 & \\
\hline $9 / 0$ & rq & جاق & \\
\hline $1 / 1$ & 9 & 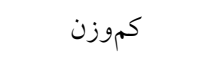 & وضعيت فيزيكى بدن مادران بر اساس BMI در كودكان تحت \\
\hline$r y / \Lambda$ & irk & طبيعى & مطالعه \\
\hline$r V / 9$ & rII & 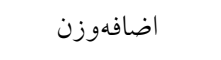 & \\
\hline$r r / 9$ & rr & جاق & \\
\hline$\cdot / 4$ & r & 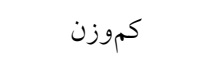 & وضعيت فيزيكى بدن بدران بر اساسBMI در كودكان تحـت \\
\hline$\varphi \vee / r$ & rar & 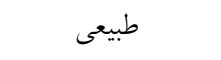 & مطالعه - الم \\
\hline$r 9 / 1$ & 194 & 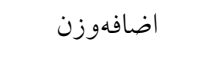 & \\
\hline N/1 & ra & جاق & \\
\hline$V / r$ & r. & p $3<$ ro.. & وضعيت وزنى كودكان در هنخام تولد \\
\hline$\Lambda 9 / \mathrm{V}$ & rAY & 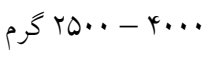 & \\
\hline 0 & r^ & 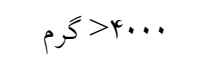 & \\
\hline
\end{tabular}

جدول †: ارتباط بين وزن هنكام تولد و وضعيت آنترويومتريك كو دكان تحت مطالعه

\begin{tabular}{|c|c|c|c|}
\hline جاق & اضافهوزن & طبيعى & \\
\hline 1 & 1 & rq & م >rQ.. \\
\hline r. & ry & rq. & كر ro... - r... \\
\hline$r$ & r & r & Fر \\
\hline
\end{tabular}

نشريه علمى يثروهشى دانشًاه علوم بزشكى البرز، دوره ع، شماره T، بهاروهب| 
توسعهيافته كردد. بنابر اين شايد بتوان نتيجه كرفت كه سبك زنـدكى

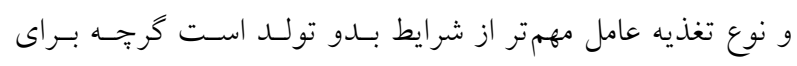

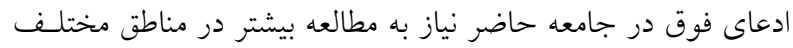
نكته مهمى كه در اينجا به جشم مى خــورد ميـزان اضـافهوزن و و

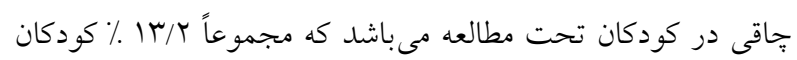

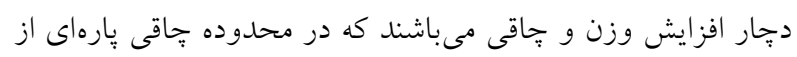

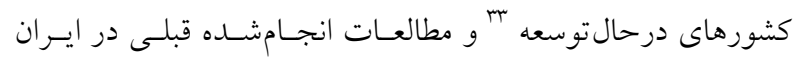
است اما ازآنجاكه مطالعه حاضر در مناطق روستايى انجامشده انتظار

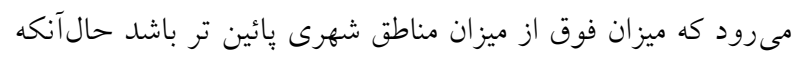

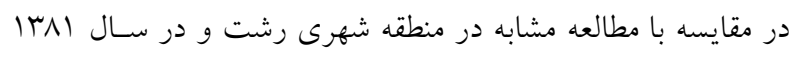

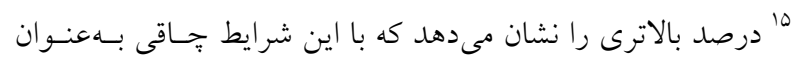
يك معضل در سنين كودكى در اين منطقه جغرافيائى قابل ذكر است.

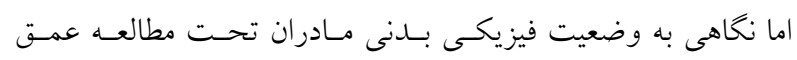

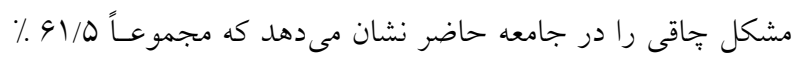

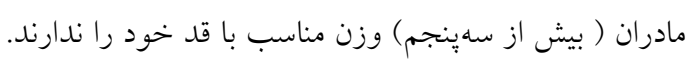

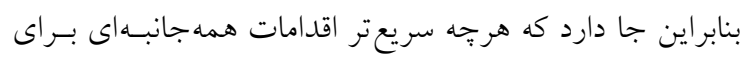

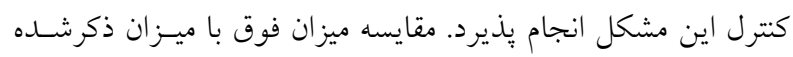

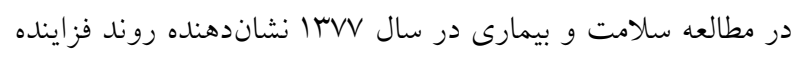
بسيار سريع جاقى در جامعه روستايى مى باشد كه بالطبع ايسن ميـزان

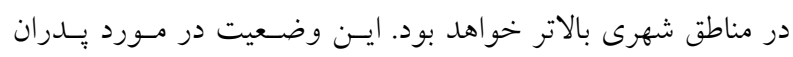

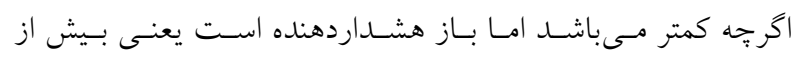

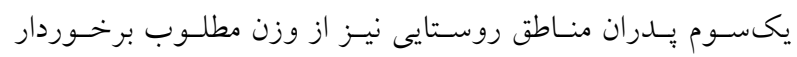

در بايان با توجه به اهميت جاقى و كنترل آن در سنين كـودكى

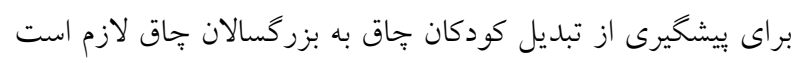

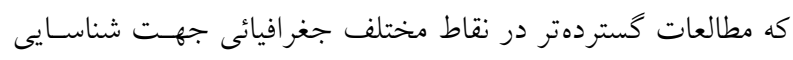

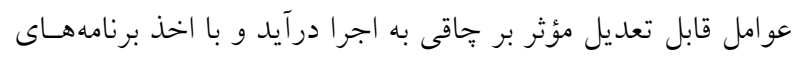

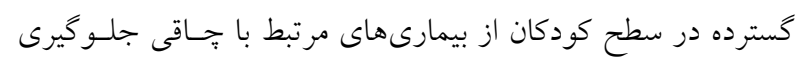

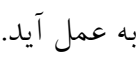

نتيجه گيرى

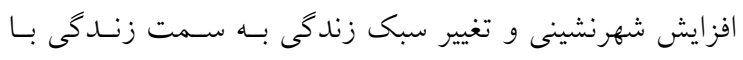
فعاليت كمتر در كنار تغيير تغذيه جهت استـفاده بيشـتر از غـذاهاى

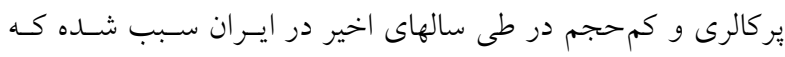

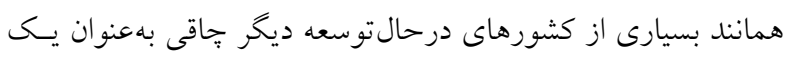

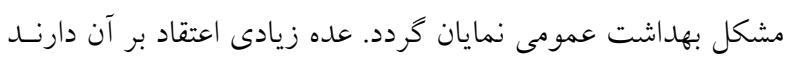

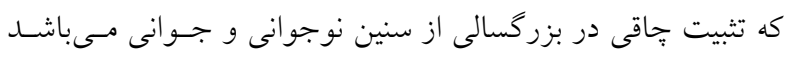

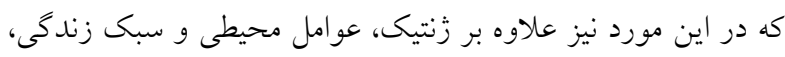

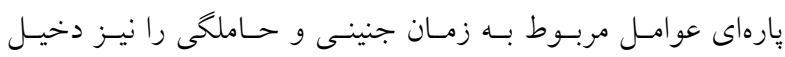

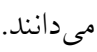

يكى از اين عوامل كه موردبحث و مجادله زياد قرارگرفتسه وزن

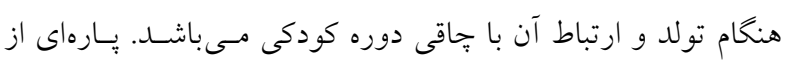

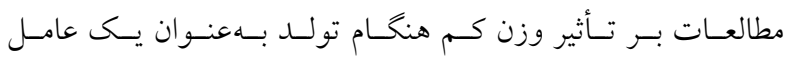

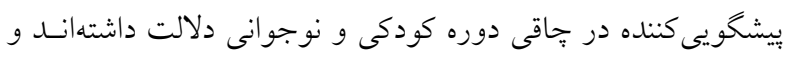

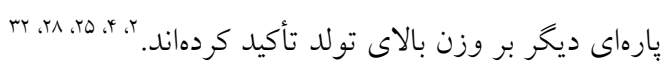

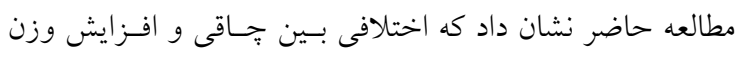

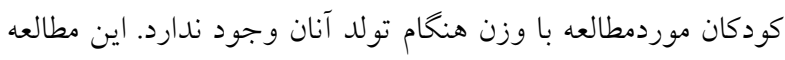

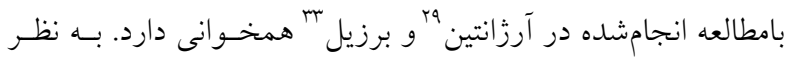
مىرسد در كشورهاى توسعهيافته كودكان LBW با مصرف غـــاهاى

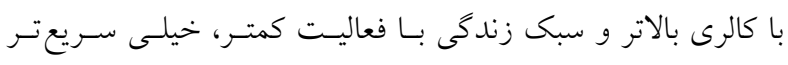

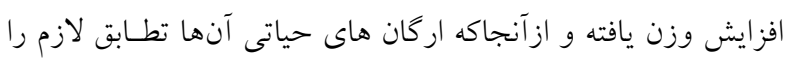

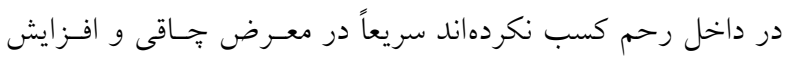

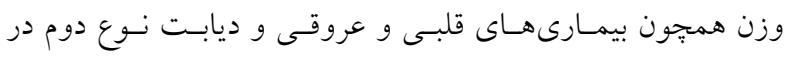

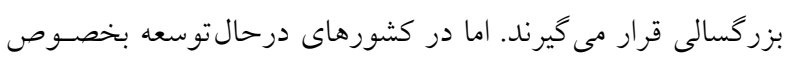

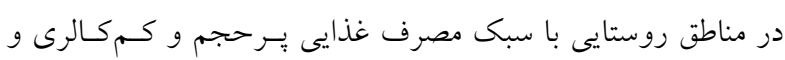

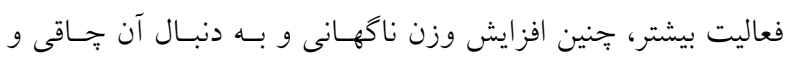

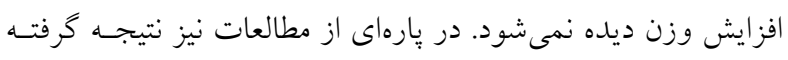

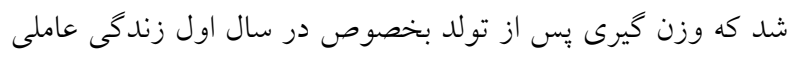

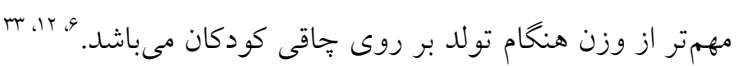

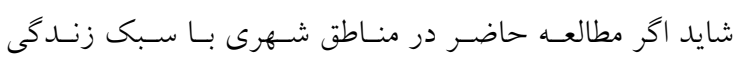

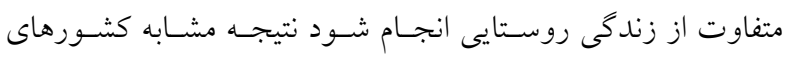



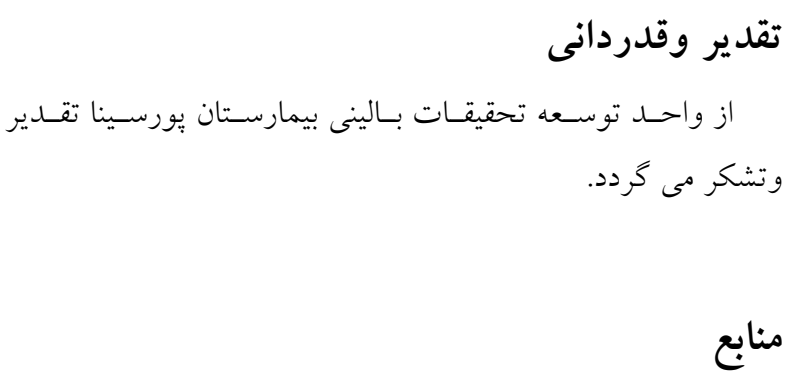

1. Mohtasham Amiri Z, Maddah M. Prevalence of overweight and obesity among female medical students in Guilan-2003. Iranian Journal of Endocrinology and Metabolism. 2006; 8 (2) :157-162.

2. Charlotte M. Boney, Anila Verma, Richard Tucker, et al. Metabolic Syndrome in Childhood: Association with Birth Weight, Maternal Obesity, and Gestational Diabetes Mellitus. Pediatrics, 2005; 115; e290-e296.

3. Kang HT, J u Yes, park KH, Kwon YJ, Im HJ, paek DM, Lee HJ. Study on the relationship between childhood obesity and various determinants, including socioeconomic factor s, in an urban area. $2006 \mathrm{Sep}$; $39(8) ; 371-8$.

4. Hirschler V, BugnaJ, Roque M, Gilligan T, Gon zalezc. Does Low Birth weight predict obesity/ Overweight and metabolic syndrome in elementary school children? Arch Med Res. 2008 Nov; 39(8):796-802.

5. R Kruger, HS Kruger and UE MacIntyre. The determinants of overweight and obesity among 10- to 15year-old schoolchildren in the North West Province, South Africa - the THUSA BANA (Transition and Health during Urbanization of South Africans; BANA, children) study. Public Health Nutrition: 2006, 9(3), 351358.

6. Nikki J Blair, John M D Thompson, Peter N Black, et al. Risk factors for obesity in 7-year-old European children: the Auckland Birth weight Collaborative Study. Arch Dis Child 2007; 92:866-871.

7. Mo-suwan L, Junjana C, Puetpaiboon A. Increasing obesity in school children in a transitional society and the effect of the weight control program. Southeast Asian J Trop Med Public Health. 1993 Sep; 24(3):590-4.

8. Malik M, Bakir A. Prevalence of overweight and obesity among children in the United Arab Emirates. Obes Rev. 2007 Jan; 8(1):15-20.

9. Onis M, Blossner M. prevalence and trends of overweight among preschool children in developing countries. Am Jclin nutr 2000:72:1032-9?

10. Mius A, Strauss PS. Risk and consequence of children and adolescence obesity. Int J Obes, 1999; 19: 223-228.

11. Mijailovic V, Micic D, Mijailoui M.Effect of childhood and adolescence obesity on morbidity in adult life. Int $\mathrm{J}$ Pediatr Endocrinol Metab, 2001; 17: 1339-1344.

12. C Corvala'n, 1 CO Gregory, 1 M Ramirez-Zea, et al. Size at birth, infant, early and later childhood growth and adult body composition: a prospective study in a stunted population. International Journal of Epidemiology 2007; 36:550-557.

13. Mohamadi F, Mirmiran B, Allah-verdian S, et al. Prevalence of obesity and overweight among 3-10 years old children in East Tehran and its association with dietary intake. $6^{\text {th }}$ National Congress of Nutrition in Iran, Tehran, Feb 2000, 39.

14. Sayyari A, Sheikhol-eslam R, Kolahdouz F, et al. Prevalence of obesity in under 5 years children in urban and rural area of Iran. $6^{\text {th }}$ National Congress of Nutrition in Iran, Tehran, Feb 2000, 41.

15. Mohtasham-Amiri Z, Mohamadi-Nezhad E, Berenjkar M, Dastghous A. Anthropometric Indices among preschool sges in Rasht. Thesis for General practitioner, 2002, register No 872.

16. Dorosty AR, Siassi F, Reilly JJ. Obesity in Iranian children. Arch Dis Child, 2002 Nov; 87(5): 388-91.

17. Azizi F, etal. Final Report of Lipid and Glucose Study. Research Institute for Endocrine Science. In: http://sbmu.ac.ir/?siteid=196\&pageid=17849.

18. Dorosty A R, Baygi F, Eshraghian M R. Prevalence of obesity among school children in Neishabour (2005). J Qazvin Univ Med Sci. 2008; 12 (1) :73-79[In Persian]

19. Taheri F. Prevalence of obesity and it relationship to some socioeconomic factors in primary school children in Birjand( 2002). Journal of Birjand University of Medical Sciences, 2002,9(1): 19-22. [In Persian]

20. Fakhrzadeh H, Bagheri AH, Hamidi A,et al. Obesity and Cardiovascular risk factors in Iranian children. Iranian Journal of Diabetes and Metabolism,2004;3(2):175-183. 
21. shahgholian $\mathrm{N}$, aein $\mathrm{F}$, deris $\mathrm{F}$. 90th percentile of body mass index (BMI) and some obesity risk factors among 7-12 years old school children, Chaharmahal \& Bakhtiary, 2002. J Shahrekord Univ Med Sci. 2004; 5(4):42-48. [In Persian]

22. Karaji Bani M., Montazerifar F, Mohammadi M, Dashipur AR.The prevalence of obesity and wasting in primary school girls in the city of Zahedan. Tabib-eShargh, 2004;6(4): 289-296. [In Persian]

23. Kang HT, J u Ys, park KH, Kwon YJ, Im HJ, paek DM, Lee HJ. Study on the relationship between childhood obesity and various determinants, including socioeconomic factor s, in an urban area. Korean J Prev Med. 2006, p; 39(5):371-378.

24. Gunnarsdottir I, Thorsdottir I. Relationship between growth and feeding in infancy and body mass index at the age of 6 years. Int J Obes Relat Metab Disord. 2003dec; 27(12): 1323-7.

25. John J Relly, Julie Armstong. Ahmad R Dorosty, Pauline M Emmett, A Ness, I Rogers, Colin Steer, Anderea Sherriff and for the Avon Longitudinal Study of parents and Children Study Team. Early life risk factors in childhood: cohort study. BMJ 2005; 330; 1357.

26. Ken K L Ong, Marion L Ahmad, Pauline M Emmett, Michael A Preece, David B Dunger. Association between postnatal catch-up growth and obesity in childhood: prospective cohort study. BMJ2000; 320; 967-971.

27. Grummer-Strawn LM, Mei Zugeo. Does breastfeeding protect pediatric overweight? Analysis of longitudinal data from the centers for disease control and prevention pediatric nutrition surveillance system. Pediatrics 2004; 113(2): 81-6.

28. Butte NF. The role of breastfeeding in obesity. Pediatr Clin North Am 2001; 480: 189-98.

29. Tessa J Parsons, Chris Power and Only Manor. Fetal and early life growth and body mass index from birth to early adulthood in 1985 British cohort: longitudinal study. BMJ, 2001; 323; 1331-1335.

30. Taras M, Ferris AM, Himmergreen DA. Rodrigus N. Child obesity: the gentic environmental as infants. Res Clin Endocrinol Metab 1999; 13(1): 31-46.

31. Power, L Li, O Manor and G Davey Smith. Combination of low birth weight and high adult body mass index: at what age is it established and what is its determinant. Journal of Epidemiology and Community Health 2003; 47:969-973.

32. Eriksson, J.; Forson, T.; Tuomilehto, J.; Osmond, C.; Barker, D. Size at birth, childhood growth and obesity in adult life. International Journal of obesity (2001) vol 25, No $5,735-740$.

33. Y Abe, T Kikuchii, K Nagazakii, et al. Lower Birth Weight Associated with Current Overweight Status Is Related with the Metabolic Syndrome in Obese Japanese Children. Hypertens Res 2007; 30: 627-634.

34. Tomé FS, Cardoso VC, Barbieri MA, Silva AA, Simões VM, Garcia CA, Bettiol H. Are birth weight and maternal smoking during pregnancy associated with malnutrition and excess weight among school age children? Braz J Med Biol Res. 2007 Sep; 40(9):1221-30. 